\title{
On the Causes and Consequences of Divorce
}

\author{
ALESSANDRO BALESTRINO \\ CINZIA CIARDI \\ CLAUDIO MAMMINI
}

\section{CESIFO WORKING PAPER NO. 2347 \\ CATEgory 3: SOCIAL PROTECTION \\ JULY 2008}

Presented at CESifo Area Conference on Employment and Social Protection, May 2008

\footnotetext{
An electronic version of the paper may be downloaded

- from the SSRN website: Www.SSRN.com

- from the RePEc website: $\quad$ www.RePEc.org

- from the CESifo website: $\quad$ www.CESifo-group.org/wp
} 


\title{
On the Causes and Consequences of Divorce
}

\begin{abstract}
In most Western economies, the flourishing of the Welfare State has coincided with a decline of the role of the family: divorce has been introduced, and the number of marriages has decreased. We suggest that a taboo against divorce was part of the informal safety net in a period when social protection was provided by the family. Once the State started offering suitable alternatives, the taboo was no longer expedient, and was dropped. For the same reasons, marriage has become less popular. We further notice that divorce is an extremely costly process, and once allowed it may act as an independent reason for the reduction of the number of marriages. This latter result is especially evident under the assumption that agents subjectively evaluate the probability of facing a divorce using an availability heuristic.
\end{abstract}

JEL Code: J12, D10, D70, D81.

Keywords: divorce, marriage, availability heuristic.

\author{
Alessandro Balestrino \\ University of Pisa \\ Department of Economics \\ Via Serafini 3 \\ Italy - 56126 Pisa \\ balestrino@sp.unipi.it
}

\author{
Cinzia Ciardi \\ Azienda USL3 \\ U.O. Formazione \\ Italy - Pistoia \\ cinzia.ciardi@libero.it
}

\author{
Claudio Mammini \\ University of Pisa \\ Department of Social Sciences \\ Italy - Pisa \\ mamminiclaudio@interfree.it
}

June 23, 2008

An earlier version of the paper was presented at the 2008 CESifo Employment and Social Protection Area Conference in Munich (Germany). We thank A. Amegashie, L. Cappellari, A. Casarico, R. Dur, K. Konrad and S. Valdes Prieto for their comments. The opinions expressed in this paper are those of the authors and do not necessarily reflect those of the Azienda USL3 and the Azienda Sanitaria Locale ASL5. 


\section{Introduction}

Isabel Archer, the heroine of Henry James' novel "The portrait of a lady", ${ }^{1}$ is a young American heiress living in Europe. She refuses a marriage offer by a fascinating English gentleman and another by a brilliant American industrialist, and ends up marrying an American expatriate in Italy. He is a superficially charming person who turns out to be instead rather dull, and, predictably, only interested in her money. Although she comes soon to realise the harshness of her situation, and to suffer from it, she endures her plight and in fact manages, with a flourish of brinkmanship, to strike out a uneasy alliance with her otherwise estranged husband in defending the appearance of a happy marriage. At the end of the story, we leave her in the middle of an inner fight, slowly building up the strength to go against her husband's will. Divorce never crosses her mind: in fact, at the very end of the book, she refuses an offer to elope with her former American suitor, still in love with her, and goes back to her husband.

In the novel, the action is set in the late XIX century. However, until not many years ago most women would have fully subscribed to Isabel's behaviour, and, given similar circumstances, would have performed the same precarious balancing act. Today, we can understand Isabel only if we put her in historical perspective. That the author portraits her as having the means to decide for herself and all the same not finding the strength to do it, is actually a powerful testimony of how strong was at the time (and later as well) the social stigma attached to divorce. $^{2}$

This paper takes up the question of why divorce has become socially acceptable and legally permissible in recent years after centuries of stigmatisation $;^{3}$ further, we investigate the impact

\footnotetext{
${ }^{1}$ Henry James (1843-1916), brother of the philosopher and psychologist William, is one of the greatest figures in the English literature (he himself was American, but lived in England for almost his entire adult life). He is credited with establishing the novel as a recognized literary genre, as opposed to a form of entertainment.

${ }^{2}$ In the 1996 film taken from James' book, directed by Jane Campion, the story ends before Isabel decides whether to go back to his husband or not - in the 20th century, it was permissible to imagine an open ending.

${ }^{3}$ Divorce was not common, but not always explicitly forbidden in the ancient Western cultures; restrictions against it began roughly with Constantine (who was Roman Emperor from 306 to 337 and famously initiated the evolution of the empire into a Christian state) and became stronger over the centuries as the church took jurisdiction over all the issues pertaining to marriage. The restrictions have lasted for centuries. For example, in Italy, divorce was illegal until the 1970s; in the UK, it was legally possible since the 1930's, although it was clearly frowned upon, and a major liberalisation was realised in the early '70s; in the US divorce has never been really prohibited, but became a relevant phenomenon only starting from the '70s, when unilateral divorce was introduced.
} 
that the availability of divorce has had on marriage. This latter point is of some interest because one might argue that the introduction of divorce is a potential deterrent to the reduction of the number of marriages: to the extent that divorce offers a way out of a mismatched marriage, it should decrease the costs of marrying. However, the evidence does not support this line of reasoning, as marriages have continued to fall in number despite the large popularity of divorce. We offer an argument in the opposite direction, casting divorce as a further reason for not marrying. ${ }^{4}$

To accomplish the task we are pursuing, we develop a two-fold argument:

- First, we suggest at a general level that the deep transformation of the Western societies in the last forty years has favoured both the introduction of divorce and the reduction of marriages; while in the past the family was the sole provider of many services (basic education and health-care, insurance, old-age support, etc.) today both the State and the market offer important alternatives (public and private education and health-care, public and private insurance and pensions, etc.). As a consequence, the role of the family has declined, and less people choose to marry; at the same time, the taboo against divorce has been dropped, as there is no need to protect the family at all costs. ${ }^{5}$

- Second, we notice at a more specific level that the costly nature of the divorce process may act as an additional and independent deterrent to marriage; once people anticipate that their marriage may end up in a divorce, they may be less prone to marry, and choose a looser form of union (say, cohabitation), if they estimate a very large probability of divorce and are aware of its high costs. A key factor here is how agents form their expectations on how their marriage will turn out; we compare a version of the model with agents capable of rational expectations with a version in which they use the availability heuristics as defined by Tversky and Kahneman (1982b), ${ }^{6}$ and argue that the predictions of this latter version are consistent with the main stylized facts.

\footnotetext{
${ }^{4}$ This point is made also by Konrad and Lommerud (2008). Their focus is on the role of redistributive taxation as an incentive to marry - in this case acting as a way of reducing divorce costs.

${ }^{5}$ For a recent detailed investigation of the interplay between the State and the family as alternative providers of insurance, and its effect on family formation and dissolution, see Anderberg (2007).

${ }^{6}$ Briefly, people are said to rely on availability heuristics when they "assess ... the probability of an event by the ease with which instances or occurences can be brought to mind" (Tversky and Kahneman, 1982b, p. 11). Unfortunately, the availability of the facts stored in our memory is not necessarily related to the frequency with which they actually happened; we remember more easily facts that have somehow solicited an emotional
} 
In Section II, we will illustrate in more details the above arguments and establish some links with the existing literature, before moving to a formal analysis in Sections III and IV, and then to a few concluding remarks in Section V.

\section{Background}

The economic literature on divorce has been heavily influenced by Becker's pioneering work on family economics. According to Becker (1991) the main determinants of divorce are to be found in the couple's earnings differentials; for example, high-earning women gain relatively little from a marriage, since the small differential implies that there is less scope for an efficient sexual division of labour, and have a stronger fall-back position in case of divorce. On the whole, then, a beckerian perspective suggest that high-income, well-educated women are more prone to divorce. We take here a complementary perspective, as we look at why divorce has become permissible at a certain point in history, rather than focusing on the nature of divorce once it has been established. To put it differently, the beckerian focus is on the motivations and the costs of divorce in our contemporary society; we look mostly at how changes in the structure of society have made divorce possible. Our emphasis lies in particular on how the societal changes over the past few decades impact on the relative power of men and women within a marriage (see Beck and Beck-Gersheim, 1995), focusing more on the difference, or lack thereof, in the source of earning than in the level - although clearly variations in sources will normally reflect themselves into variations in level.

To illustrate our arguments, to be developed formally in the next two Sections, we briefly sketch the recent evolution of the family as society has moved from its agricultural past through a transitional phase of early industralisation to its contemporary post-industrial structure. Of course, we simplify the story as much as we can, taking somewhat extreme views in order to save space and time.

\section{A quick look at the evolution of the family}

In a pre-industrial society, the market has a very limited role. Both men and women are engaged in self-production, and the division of labor across genders does not necessarily reflect the inside

response or are especially out of the ordinary. Hence, availability heuristics imply a tendency to overestimate certain probabilities. We return at length on this point in Section IV below. 
home/outside home cleavage. The family is in fact very much a business organisation running e.g. a farm. It is important to notice that men and women, although they fulfill different tasks, contribute to the prosperity of the family in a symmetric fashion, in the sense that they all work within the family itself. Their claim on the commodities entering the family consumption basket comes from the same source. It is difficult here to speak of disparity in earning levels, as there is no objective metric through which the value of production can be assessed.

This sort of structure has historically changed with the advent of the industrialised society, in which the man starts working for the market while the woman attends to the household chores, and the consumption goods are acquired through the market (as opposed to self-production). In this case, we do have an evident earning disparity, due to the fact that market production is rewarded in money units, whereas home production is not. We want to focus however on a particular aspect of this disparity. While it is obvious that the sexual division of labour reflects in principle an efficient task allocation routine, it is also obvious that it implies an asymmetry in the power relationship, should any dispute arise between the partners. As the consumption basket is no longer self-produced, but only accessible via the market, and given that only the man has a direct claim on money income (the instrument needed to access the commodity market), the fall-back position of the two partners in case of disagreement is extremely unequal, despite the fact that the home production of the women is just as important as the market production of the man as far as the well-being of the family is concerned.

Finally, in what we may call the post-industrial society, both men and women work for the market, and share the household work or hire on the market a person to do it. There is less scope for a sexual division of labour, as comparative advantages tend to be modest inasmuch as marketable skills are more homogenous across genders. The difference in terms of the level of money income that the two genders may obtain is reduced (although not eliminated), and, most importantly from our point of view, the symmetry is re-established in terms of the source of purchasing power. This generates a different scenario than in the industrial society. In the latter, the shadow value of home-production might have been greater than the value of the market production, still the woman would have had less power in any dispute. In the postindustrial society, for both genders power comes from market earnings, whose levels can be compared to determine the relative fall-back positions, as is usually emphasized in beckerian analyses of divorce. 


\section{The family and the State as alternative providers of social protection}

So far, we spelled the implication of the family working arrangements (who works at home and who works outside) for the pattern of entitlements to the goods that enter the consumption bundle. The consumption basket of a family includes however also services, not only goods. Some of these services, like love or companionship, are intangible and can only be found within a family. Material services, like child care, mutual insurance, old-age security, have also been for centuries provided within the family, but in the last five or six decades the Welfare State has become a relevant player in this sector. The working arrangement has implications also for the access to certain services when they are provided by the Welfare State.

To see this, notice first that the services we mentioned constitute a safety net, a form of social protection, for the society as a whole; they are mostly insurance services, for which markets are known to be typically incomplete. In the pre-industrial society these services were provided within the family like everything else. With the passage to industrialisation, some of these services can be provided by the State; a relevant example is the pension system, that entitles anybody who works in the market to a pension once retired. Note that the asymmetry which we saw as characterising the industrial family is still present here. The State crowds out the family as the provider of old-age security, but the claim to this service is reserved to those who work outside the family, that is men. Women can access the survivors pension scheme, but only if married to the men originally entitled to the pension. Men have easier access to outside services than women - which again reinforces a tendency to differentiate across genders the fall-back positions in case of a dispute. Finally, in the post-industrialised family, both genders have independent access to the services, and symmetry is again restored.

We claim that the availability of social protection services from the Welfare State has made divorce possible, first by making it socially acceptable, and then legally permissible. In line with the mainstream economic literature on divorce referred to above, we intend the legal norm as following and reflecting the social customs: a law introducing or facilitating divorce will be passed only when the social attitude of the voters is favourable to such a law. In turn, since a social norm has the primary task of enhancing the prosperity of a community, ${ }^{7}$ it will be established only if a sufficiently large number of members perceive an advantage in following it, in this case if enough people are in favour of divorce.

\footnotetext{
${ }^{7}$ See e.g. Akerlof (1982) and Coleman (1990).
} 
So, the key question is indeed, when are people in favour of divorce ${ }^{8}$ In the next Section, we will argue that, as we move from the traditional through the industrial to the post-industrial family, the attitude towards divorce changes, becoming progressively more favourable. From being a threat to the social protection network, which was constituted exclusively by the families in a traditional society, divorce becomes for the industrial and especially post-industrial families, an option that, potentially, makes people better-off by allowing an avenue of escape from mismatched marriages. So, people modify their preferred option (become supporters, rather than opponents, of divorce) as the circumstances change over the years.

Before moving to the analysis in Section III, we would like to make a few remarks on yet another point (to be discussed formally in Section IV). We said that divorce constitutes a "potentially" useful option. Of course, it is also a costly option. In recent years, the costs of divorce have decreased substantially; legal fees are less than they used to be, the time required for finalising the process is shorter, the social stigma has been removed at least partially, etc. This relative reduction should however not blind us to the fact that divorce remains, in absolute terms, extremely costly on the psychological side; it generates a painful condition from which one may in fact be never free (Beck and Beck-Gernsheim, 1995). When a person divorces, the connection with one's former partner will take a long time to be really severed, if ever. To see this, it is sufficient to consider that the main source of divorce costs is the fact that during the years of marriage the couple has established rights over a number of household public goods, and as long as these goods still exist after the divorce, new rules have to be found for letting the former spouses continue to exercise their rights, or for compensating one of them if he or she forfeits them. So, divorcees have to agree on what to do with joint properties, such as houses or cars, and in case of children, they have to agree on how to share custody, parental responsibilities, etc. The conflict that may, and normally will, arise between the spouses at the time of divorce is extremely painful. The "agreements" have often to be imposed by a judge. Divorce law provides several pre-ordained solutions to the conflict (varying from country to country, although there are common features such as assigning the children to the mother, ${ }^{9}$ etc.), and this may help insofar as it reduces the duration of the conflict. However, it is clear

\footnotetext{
${ }^{8}$ There are of course many types of divorce. In the formal model, we will focus for simplicity on unilateral, no-fault divorce.

${ }^{9}$ That would be true of Western countries; in Muslim countries, the children are normally assigned to the father.
} 
for example that divorced parents will always retain some sort of link with the each other (they will remain the parents of their children, no matter what); fresh opportunities to rekindle the conflict, and the attendant costs, may arise for a long time. A divorced person does not revert to single status: he or she is forever an ex-spouse.

Given this, it is possible to argue that the very possibility of divorce may in fact make marriage a less, rather than a more, popular option. If a person estimates a sufficiently high probability that his or her marriage ends up in a divorce, the costs to be faced in that case are so high that it makes sense to choose an alternative living-in option (say cohabitation). And we saw, (fn. 6) that the availability heuristics induces people to overestimate events whose occurrence is particularly easy to remember - among them, one might argue, divorces. ${ }^{10}$

\section{The emergence of divorce under changing family structures}

To begin with, we consider a very simple finite-horizon two-period economy. ${ }^{11}$ In the first period, agents decide whether to marry or stay single; in the second whether to stay married or divorce. Decisions are taken on the basis of lifetime utility. In general, the per-period utility function includes three items: a consumption (net income) flow $(y)$, a material services flow $(x)$, and an immaterial services flow $(Z)$. We do not specify a period index, since flows do not depend on periods, and we ignore discounting. The population comprises $N$ men and $N$ women; then, there will be at most $N$ couples. All agents have the same utility function; all men earn the same, and so do all women, but we allow for gender-specific differences in earnings/consumption levels, as well as in the flows of both kinds of services. We do not explicitly model search and matching; we simply assume that, in the first period, each agent has a once-in-a-lifetime opportunity to meet another agent of the opposite gender: if they are willing to marry each other, the marriage will take place, otherwise they will stay single (we live it unspecified whether they choose cohabitation, or an ever looser form of relationship, or stay separated).

An important element for the analysis is the extent to which agents have compatible personalities and enjoy each other's company or not. In our simplified setting, the only chance they

\footnotetext{
${ }^{10}$ In fact, Tversky and Kahneman's (1982a, p. 164) first example of availability heuristics is as follows: "...one may assess the divorce rate in a given community by recalling divorces among one's acquaintances".

${ }^{11}$ Later, we will strenghten the dynamic nature of the model in order to investigate the evolution of marriage behaviour across generations.
} 
have to get to know each other is during the first period; if a man marries a compatible-type woman the flow of immaterial services $Z$ takes a positive value, $Z=\zeta>0$, otherwise, it takes a negative value $Z=-\zeta<0$. In this latter case, if divorce is available, they might want to contemplate its feasibility in the second period. ${ }^{12}$ The probability, for each agent, to end up in a good or in a bad match will be key for the subsequent analysis. A realistic, and at the same time simple, way of modelling this probability is to assume that it is idiosyncratic to the couple. There are so many possible personality variants, so many diverse circumstances under which people meet and marry, so many different senses in which two people may be compatible with each other, that it seems reasonable to assume that each couple has a different chance of forming a successful union. Hence, letting $\nu^{i j}$ denote the probability of a successful marriage for a generic couple formed by agents $i$ and $j$, the expected value of the immaterial service flow for agent $i$ is

$$
E\left(Z^{i}\right)=\nu^{i j} \zeta+\left(1-\nu^{i j}\right) \zeta=\left(2 \nu^{i j}-1\right) \zeta
$$

The true probability is, plausibly, not known to the agents. So, they have to guess it, and compute the expected value of the immaterial services flow on this basis. For now, we do not specify the mechanics of the guess; we only notice that each agent will make the guess in his or her own way, using different procedures for collecting information and elaborating it, etc. At one extreme, there might be agents endowed with perfect foresight, who predict the true value of the probability of successful marriage with pinpoint accuracy; moving toward the other extreme, there might be agents who err in the direction of underestimating this probability to an extent that depends on how much they are relying on availability heuristics. In the next Section, we will study the formation of this estimated probability in a more detailed way; for now, we proceed by taking it as given. Hence, denoting the subjective probability by $p^{i j}$, we have that the perceived expected value is

$$
z^{i}=\left(2 p^{i j}-1\right) \zeta
$$

We now have all the elements to write the per-period utility function; if we take $x$ and $z$ to measure the income equivalents of the service flows, and assume risk-neutrality, we write

$$
u^{i}=y^{i}+x^{i}+z^{i} .
$$

\footnotetext{
${ }^{12}$ In a more complete model, we would have added a period in which the agents search for their preferred partner, thereby limiting the risk of a subsequent divorce. However, this would not have altered the qualitative results in any way. A study which explicitly focuses on search processes and divorce is Cameron (2003); for more references to the search models of courtship and marriage, see e.g. Balestrino and Ciardi (2008).
} 
Depending on the type of the family, the access to the flows varies in different ways when the agents change marital status. We will consider the three types in turn.

We focus now on the process whereby the agents, in order to decide whether to marry or not, compare their lifetime expected utilities from staying single and from marrying, and choose the higher one. In order to study the endogenous formation of divorce law, we proceed as follows:

- we investigate the agents' choices when divorce is not allowed;

- we ask whether their well-being would be improved by the introduction of divorce; agents for whom the answer is "yes" would vote in favour of a law allowing divorce; agents for whom the answer is"no" would vote against;

- we suppose that a divorce law is proposed, and check whether a majority for or against it can be formed:

- if divorce law is not approved, we end the analysis;

- if divorce law is approved, we ask whether the presence of divorce alters the incentives to marry.

\section{The pre-industrial family.}

A single agent obtains, in each period, the consumption flow $y$; typically, it will be self-produced. The agent enjoys neither material nor immaterial services if non-married; he or she does not benefit of, say, the mutual insurance available for the members of a family (an example of material service) or of the companionship that a spouse can offer (an example of immaterial services). So, in each period the utility function of a single agent (male or female) in a preindustrial society can be written

$$
\bar{u}^{i}=y^{i}
$$

where the upper bar denotes the single status. A married agent has for simplicity the same consumption, but has also access to both kinds of services

$$
u^{i}=y^{i}+x^{i}+z^{i}
$$

Take then a man and a woman who meet. Will they marry? In the absence of divorce, either of them would marry if

$$
2\left(y^{i}+x^{i}+\left(2 p^{i j}-1\right) \zeta^{i}\right) \geq 2 y^{i}
$$


The term on the left-hand side (lhs) is lifetime utility from marriage, and that on the right-hand side (rhs) is lifetime utility from staying single: an agent who gets at least the same utility from marrying than from staying single, marries. The perceived probability of a good match, that is the probability of enjoying the companionship and love of one's spouse, will give us a criterion to compare the decisions across societal types.

We proceed then to identify the probability level above which an agent in the pre-industrial society marries, denoted $\widehat{p}^{i j}$. As long as $\zeta<x$, it is easy to see that $\widehat{p}^{i j}=0, \forall i, j{ }^{13}$ The point is that if $\zeta$ is small relative to $x$ it is obviously better to marry no matter what; even with $p^{i j}=0$ it would be worth marrying, for then (6) becomes:

$$
x^{i}-\zeta^{i} \geq 0
$$

We can thus state

Claim 1 In a pre-industrial society in which divorce is not allowed, if $\zeta^{i} \leq x^{i}$, then $\hat{p}^{i j}=0$, $\forall i, j$ - that is, all agents marry.

Would divorce be possible in this context? To answer this question, we suppose that a divorce law is proposed in the first period; agents are therefore given an ex-ante choice, i.e. they are asked whether they would like to be able to divorce, should the necessity arise in the future. Assume then that the agents know that, if $z$ turns out to be negative, he and his spouse (or she and her spouse) might split in period 2 at a cost $\gamma>0$. Then, a married agent's expected utility would be

$$
2 y^{i}+p^{i j} 2\left(x^{i}+\zeta^{i}\right)+\left(1-p^{i j}\right)\left(x^{i}-\zeta^{i}-\gamma\right)
$$

Clearly, the expected utility of a person married for both periods exceed that of one who divorces in period 2; the difference between the expected utilities without and with divorce is

$$
x^{i}-\zeta^{i}+\gamma>0
$$

As we argued in the previous Section, $\gamma$ is bound to be relative large; however, even if $\gamma=0$, (9) would be positive as a consequence of (7). The point is that by divorcing the person loses the material services flow, which is the reason why he or she married in the first place: divorce is not really an opportunity.

\footnotetext{
${ }^{13}$ The assumption that $\zeta<x$ makes good sense in a pre-industrial world. Agents will subjectively assign much more value to the flow of material services, that are key to their subsistence, rather than to the flow of immaterial services.
} 
This analysis is thus consistent with the observation that in traditional communities marriage is widespread and divorce is stigmatised. Marriage has an all-important function to serve; it is the only access to the provider of specific and relevant services that constitute the very safety net of the whole society. The social attitude is one of great respect for marriage, which is strongly protected by the social norms. The stigmatisation of divorce is one such custom. In this social climate, a law permitting divorce will never be accepted. Suppose in fact that such a law is proposed in the first period, and that it requires a simple majority to pass (as there are $2 N$ agents in the society, this requires that at least $N+1$ vote in favour). In the present setting, all voters would cast their ballott against it: that is, if the agents are given an ex-ante choice of whether to allow a divorce law or not, they would all vote it down. We have thus:

Claim 2 In a pre-industrial society, divorce law can never be established.

\section{The industrial family}

This family type is chacterised by an asymmetry between genders. Letting the superscripts $m$ and $f$ denote a generic man and a generic woman, respectively, we take it that a single man gets utility $\bar{u}^{m}=y^{m}+\bar{x}^{m}$ per period, whereas a single woman has instead utility $\bar{u}^{f}=y^{f}+\bar{x}^{f}$, again per period; presumably, $y^{m}>y^{f}$ and $\bar{x}^{m}>\bar{x}^{f}$. Since the woman loses her income when she marries, the husband will have to transfer some of his own net income flow; we also take it that the material services flow for married couples is the same across genders, and is larger than the flow accessible to single men:

$$
x^{m}=x^{f}=x>\bar{x}^{m}
$$

Thus, a married man gets, in each period, utility

$$
u^{m}=y^{m}-s^{f m}+x+\left(2 p^{m f}-1\right) \zeta
$$

where $s^{f m}$ is the (possibly couple-specific) side-transfer; a married woman gets instead

$$
u^{f}=s^{f m}+x+\left(2 p^{f m}-1\right) \zeta .
$$

A meeting between a man and a woman will end up in marriage if $y^{m}-s^{f m}+x+\left(2 p^{m f}-1\right) \zeta \geq$ $y^{m}+\bar{x}^{m}$ for men and $s^{f m}+x+\left(2 p^{f m}-1\right) \zeta \geq y^{f}+\bar{x}^{f}$ for women. In general, men will want to make the transfer as small as possible. Define implicitly $\widehat{s}^{f m}$ as the transfer that makes a woman 
$f$ just indifferent between marrying a man $m$ or stay single, i.e. $\hat{s}^{f m}+x+\left(2 p^{f m}-1\right) \zeta=y^{f}+\bar{x}^{f}$. We have:

$$
\widehat{s}^{f m}=y^{f}+\left(\bar{x}^{f}-x\right)-\left(2 p^{f m}-1\right) \zeta,
$$

which is indeed couple-specific as depends on the probability $p^{f m}$. The transfer (which we expect to be positive) should be equal to the original goods flow minus the excess material services flow $\left(\bar{x}^{f}-x<0\right)$ minus the expected value of the immaterial services flow.

We take it that the transfer equals $\widehat{s}^{f m}$. Then, all women would accept a marriage proposal; the question is, when would men do that proposal? In principle, we would want to identify the level of $p^{m f}$ above which a man wants to marry, called $\widetilde{p}^{m f}$. In order to compare the present situation we the one depicted in the previous subsection, we ask however a slightly different question, that is we look for the conditions under which $\widetilde{p}^{m f}=0$. When $p^{m f}=0$, the gain from marriage exceeds the loss if $x-\bar{x}^{m} \geq \zeta+\widehat{s}^{f m}$; substituting for $\widehat{s}^{f m}$ we get:

$$
2 x \geq y^{f}+\bar{x}^{f}+\bar{x}^{m}+2\left(1-p^{f m}\right) \zeta .
$$

Hence, we can state

Claim 3 In an industrial society without divorce law, if $2 x \geq\left(y^{f}+\bar{x}^{f}+\bar{x}^{m}+2\left(1-p^{f m}\right) \zeta\right)$, then $\widetilde{p}^{m f}=0, \forall m, f-$ that is, all agents marry.

Notice that the condition under which everybody marries is more stringent than in the preindustrial society: marriage is less desirable, because a certain amount of services is available also for singles, and because the asymmetric access to the labour market makes marriage heavier for the men. In fact, for condition (14) to be satisfied, it is important that $y^{f}, \bar{x}^{f}, \bar{x}^{m}$ are small relative to $x$, and that either $\zeta$ is small or $p^{f}$ is large (or both). In other words, marriage will (predictably) be more popular when women earn little, when the material services flow for singles is modest relative to that for married people, when agents attach little importance to the emotional aspects of marital life, and when women estimate a large probability of a successful marriage. In fact, these aspects are broadly consistent with the stylised description of an industrial society.

Consider now the introduction of divorce. Then, marriage would give to a man lifetime utility

$$
2\left(y^{m}+x\right)+p^{m f} 2\left(-\widehat{s}^{f m}+\zeta\right)+\left(1-p^{m f}\right)\left(-\widehat{s}^{f m}-\zeta-\gamma\right) \text {. }
$$


As for a woman, we have to deal with the question of how she can earn an income once divorced. The optimistic view would be that a divorced woman can re-enter the labour market and find a job with gives her the same income as if she were single. In many cases, this is far too optimistic, as industrial societies are in general not characterised by a large presences of middle-aged women in their workforce; divorced women might also have dependent children, their skills might have become obsolete, etc. We make here the extreme assumption that a divorced woman can only obtain a flow of material services (for simplicity this is indeed taken to be the same she would have if she were single), but no earned income (which the same as saying that we normalize this specific income to zero). Therefore her lifetime utility under divorce would be

$$
p^{f m} 2\left(\widehat{s}^{f m}+x+\zeta\right)+\left(1-p^{f m}\right)\left(\left(\widehat{s}^{f m}+x-\zeta\right)+\left(\bar{x}^{f}-\gamma\right)\right)
$$

In order to compute the differences in lifetime utilities for men and women with and without divorce, we compare (11) with (15) and (12) with (16). ${ }^{14}$ Men will be better-off with divorce if

$$
\widehat{s}^{f m}+\zeta>\gamma
$$

As long as the transfer to the wife and the subjective perception of the emotional value of a good match are small relative to $\gamma$ (which, it will be recalled, is large in absolute terms), this condition is not satisfied. As for women, they will be better-off with divorce if the utility gained in the second period of a mismatched marriage falls short of that gained from divorcing, that is if $\widehat{s}^{f m}+x-\zeta \leq \bar{x}^{f}-\gamma$. Substituting for $\widehat{s}^{f m}$ using (13) and simplifying, we obtain a clearer version of the same condition, namely:

$$
2 \zeta p^{f m}>\gamma+y^{f}
$$

If the subjective probability estimation of a good match as well as the subjective perception of the value of the intangible services are small relative to the cost of divorce (which includes now also the loss of income), the condition is not satisfied.

Interestingly, the divorce conditions differ for men and women; and, clearly, the cost of divorce for women is much larger that for men, so they are more adverse to it than men are. This reflects the power asymmetry which we referred to earlier, an asymmetry which turns out to have the perverse effect of making those who stand to gain the least from marriage, i.e. women, the strongest enemies of divorce.

\footnotetext{
${ }^{14}$ Notice that (11) and (12) are per-period utilities, so they have to be multiplied by two to give lifetime utility.
} 
Suppose finally that, as in the previous case, a divorce law is proposed in the first period, and that a simple majority is required to make it pass. Faced with this ex-ante choice, agents will all vote against the law if conditions (17) and (18) both fail for all men and all women. In fact, for divorce law to be rejected, it is enough that either all men or all women oppose divorce, for then a majority of $N+1$ can never be achieved:

Claim 4 In an industrial society, if either $2 \zeta p^{f m}<\gamma+y^{f}$ for all $f, m$ or $\widetilde{s}^{f m}+\zeta<\gamma$ for all $f, m$, divorce will not be allowed.

Notice that, while in the pre-industrial case divorce law was clearly doomed from the start, it is not impossible to conceive of a situation in which an industrial society might allow it. There clearly are combinations of parameters that permit the formation of a majority in favour of divorce; for example, a large value of $p^{f m}$ for some couples, combined with a small value of $y^{f}$, might made a fraction of women favourable to divorce; at the same time, there might be enough men for which condition (17) holds. The question of how likely this and similar combinations are to hold in practice is however moot. Hystorically, the case of Italy might provide a good discussion. In the 70's, when divorce was made legal, Italy still had some characteristics of an industrial society, most notably the power asymmetry within the family resulting from the employment of the husband in the labour market and of the wife at home; however, it evolved quickly into a post-industrial structure, although with a more limited labour force participation of women than in most OECD countries.

\section{The post-industrial family}

In the post-industrial society, both genders have in each period $\bar{u}^{i}=y^{i}+x^{i}$ as single, or $u^{i}=2\left(y^{i}+x^{i}\right)+\left(2 p^{i j}-1\right) 2 \zeta$ as married. So, a couple will marry if

$$
2\left(y^{i}+x^{i}\right)+\left(2 p^{i j}-1\right) 2 \zeta \geq 2\left(y^{i}+x^{i}\right)
$$

for both genders. To determine the value of the critical probability level $\check{p}^{i}$, we solve

$$
y^{i}+x^{i}+\left(2 p^{i j}-1\right) \zeta=y^{i}+x^{i}
$$

to arrive at

$$
\check{p}^{i j}=1 / 2, \forall i, j .
$$


This follows because in that case the expected value of $z$ will be zero, and thus the equality (20) will hold. Marriage in a post-industrial society is much less popular than in the other two cases. We state:

Claim 5 In a post-industrial society in which divorce is not allowed, only agents for whom $p^{i} \geq 1 / 2$ are willing to marry; actual marriages will take place when two agents, both willing to marry, meet.

The only difference between being married or not is the quality of the relationship with the partner; if one expects it to be good, he or she will marry, otherwise stays single.

Would divorce make people better-off? A person for whom divorce is possible gets $2\left(y^{i}+x^{i}\right)+$ $\left(2 p^{i j}-1\right) \zeta+p^{i j} \zeta-\left(1-p^{i j}\right) \gamma$. The expected utility with divorce allowed is thus larger than without if

$$
\zeta>\gamma
$$

Hence, supposing again that a divorce law is proposed in the first period, it will achieve the required majority (indeed a unanimous support) if the benefit from the immaterial services is larger than the cost of divorce, that is when the subjective valuation of the intangible assets of a marriage (love, companionship, etc.) is sufficiently large. The outcome of the ex-ante choice is now in favour of divorce law if (22) is satisfied:

Claim 6 In a post-industrial society divorce will be allowed if $\zeta>\gamma$.

The importance attached to the emotional, immaterial value of a marriage in our contemporary, post-industrial society, makes it plausible that the condition in the above Claim is satisfied. ${ }^{15}$

We move now to the question whether the presence of divorce alters the incentives to marry. Once divorce is allowed, a person marries if

$$
p^{i j} 2\left(y^{i}+x^{i}+\zeta\right)+\left(1-p^{i j}\right)\left(\left(y^{i}+x^{i}-\zeta\right)+\left(y^{i}+x^{i}-\gamma\right)\right) \geq 2\left(y^{i}+x^{i}\right) .
$$

\footnotetext{
${ }^{15}$ In an interesting study, LeVine et al. (1995) report that only $3.5 \%$ of the respondents to their survey in the US, and $3.7 \%$ in the UK, would have been willing to marry a person who had all the ideal quality of a partner without being in love. Corresponding figures in India and Pakistan were $49 \%$ and 50,4\%. This is in line with our claim that the role of the family as provider of social protection has declined where the Welfare State has been developed.
} 
Hence, the cut-off probability is:

$$
\check{p}^{i j}=\frac{\zeta+\gamma}{2 \zeta+\gamma}, \forall i, j
$$

Then, we have:

Claim 7 In a post-industrial society in which divorce is allowed, only agents for whom $p^{i} \geq$ $(\zeta+\gamma) /(2 \zeta+\gamma)$ are willing to marry; actual marriages will take place when two agents, both willing to marry, meet.

The possibility of divorce changes the behaviour of the agents in that it makes marriage less likely - the more so, the larger is $\gamma$. In fact, if $\gamma$ is approximately zero, then the critical probability level is approximately $1 / 2$, i.e. the same as without divorce law. If divorce is extremely accessible, then marriage behaviour does not change. We have actually argued that this is not the case $-\gamma$ is likely to be large; so, in order for agents to be willing to marry under divorce law, the perceived probability of a good marriage must be strictly larger than $1 / 2$ (whereas in the absence of divorce law $1 / 2$ was enough). If we order all agents from the one with the lowest to the one with the highest subjective probability $p^{i}$, then we can view the threshold value $\check{p}$ as partitioning the society into two groups, one comprising all those who are willing to marry $\left(p^{i}>\check{p}\right)$ and the other all those who stay single; the introduction of divorce law reduces the number of those belonging to the former group.

This conclusion invites a deeper investigation of how the presence of divorce changes marriage behaviour. We take up this issue in the next Section, using a modified version of the model employed so far.

\section{Divorce and marriage in a post-industrial society}

In the previous section, we have focused on the behaviour of each generation taken alone. Now, let us consider what happens as generations succeed each other, in particular what happens to the marriage rate when divorce is introduced in a post-industrial society. To this end, we modify our setup transforming the finite-horizon economy into an overlapping generations (OLG) economy. The analysis above carries over to the new setting as a description of the behaviour of each generation taken in isolation; however, we are now also interested in the link between generations. Normally, in OLG models such a link is provided by intergenerational transfers; here, the only element that connects the various generations is the information that 
members of the present generations can collect on the behaviour of the past ones. The behaviour we are interested in is of course the one concerning divorce, and the information comes from the actual rate of divorce of past generations.

\section{Alternative assumptions on the formation of expectations}

In the previous Section we did not specify how the agents formed their guesses on the probability that their marriage is a good one. Now, we look more closely at this issue. We will compare the case of agents who are able to perfectly forecast this probability (perfect foresight) with the one in which they use availability heuristics. Of course, the perfect foresight framework needs no presentation. A few words should instead be spent to explain the recourse to an availability heuristic in the present context. In fact, we wish to argue that, with specific reference to the marriage market, this latter assumption is at least as plausible, possibly more plausible, than that of full rationality.

The idea is that divorce is a good instance of a fact that generates an emotional response and thus tends to figure prominently in our memory. When we hear that someone we know is getting a divorce, we feel sorry for her; a kid who sees his parents divorcing will probably suffer long-term negative consequences; celebrity divorces, and the tabloids feasting on them, hit our imagination. On the other hand, lots of marriages are happy; but, since a happy marriage is not breaking news, this goes largely unnoticed. As a consequence, agents would tend to overestimate the actual occurrence of divorces, and, relatedly, also to overestimate the probability that they themselves will divorce. There are several empirical confirmations of the fact that people do use availability heuristics in real life. Casual observation suggests it: for example, it is definitely more likely to die in car accidents than in plane crashes, but since the latter are much more spectacular and as such heavily emphasized by the media, they are more easily called to mind: as a consequence, many of us are afraid of boarding a plane, but not of driving a car. Heuristics allow us to cut on decision-making costs (which is why are often employed), but they may, and often will, induce judgment errors: several experiments illustrating the mistakes descending from the availability heuristic and other judgment biases are discussed in the literature. ${ }^{16}$

Still, it would be too much to contend that availability heuristics have a general plausibility as a decision rule. It has been convincingly argued that heuristics and biases can be overcome

\footnotetext{
${ }^{16}$ For in-depth accounts of the pervasiveness of cognitive fallacies, see e.g. Kahneman et al. (1982) and Gilovich et al. (2002).
} 
by frequent players in private markets (List 2004), due to a repeated interaction effect - people can be expected to learn quickly how to behave efficiently. But the occasional nature of the act of marrying implies that the players in the marriage market do not repeat the "transaction" often enough to become "frequent players". This is why family formation and dissolution seems to be a fruitful area for exploring the implication of availability heuristics. True, it has also been argued that the family, like the market, is a place in which economic decisions are taken repeatedly through interactions between two (or more) agents, and therefore it is just as possible to assume that such agents learn over time to make efficient choices. However, this argument, which is at the heart of the so-called collective models of the family (Chiappori, 1988; Browning and Chiappori, 1998; Apps and Rees, 1999), refers to the management of an existing family, not to the formation of a new one. To be sure, its validity, within its field of application, has been challenged from many sides: for example Lundberg and Pollak (2001) have noticed how the repeated interaction argument fails to cover important and difficult decisions with long-term, largely unforeseeable, consequences and a high degree of irreversibility - say when one of the partners is considering whether to move to another city or to switch to another job. ${ }^{17}$ By the same logic, it seems even less plausible to apply the argument to family formation: there are indeed significant costs to be faced in case one would wish to reverse the decision to marry, and more generally there clearly is limited scope for repeated interaction.

Then, a perfectly rational agent $i$, when he or she meets a prospective partner $j$ a time $t$, predicts accurately the probability $\nu_{t}^{i j}$ that the eventual marriage is a "good" match: so, we have $p_{t}^{i}=\nu_{t}^{i j}$. At the opposite extreme, there is an agent who relies entirely on availability heuristics. In our setting, he will use a perception of the divorce rate of the previous generation to assess the probability of his or her own marriage ending in a divorce. Such perception will err in the sense of overestimating the actual occurrence of divorces. Assuming that at time $t-1$ there are $M$ couples, the actual rate of divorce will be zero without divorce law, and will equal

$$
d_{t-1}^{M}=\frac{\Sigma_{m=1}^{M}\left(1-\nu_{t-1}^{m}\right)}{M}
$$

with divorce law. The perceived divorce rate might be expressed as

$$
\delta_{t}=f\left(d_{t-1}^{M}\right)
$$

\footnotetext{
${ }^{17}$ To model these issues, Lundberg and Pollak (2001) advocate a non-stationary, multi-stage game in which the absence of a commitment mechanism makes inefficient outcomes possible. Simpler alternatives to the collective approach call for non-cooperative models assuming Cournot behaviour - see e.g. Konrad and Lommerud (1995) and Anderberg and Balestrino (2007).
} 
with $f(0)=0, f\left(d_{t-1}^{M}\right)>d_{t-1}^{M}$ for $d_{t-1}^{M}>0$. Then, a totally biased agent $i$, when he or she meets a prospective partner $j$ a time $t$, predicts inaccurately the probability the the eventual marriage is a "good" match by setting $p_{t}^{i}=1-\delta_{t}$.

In fact, it might be more realistic to assume that most agents lie between these two extremes, and that their assessment of the probability is governed by the following rule:

$$
p_{t}^{i}=k^{i} \nu_{t}^{i j}+\left(1-k^{i}\right)\left(1-\delta_{t}\right),
$$

where $k^{i} \in[0,1]$. As $k$ approaches unity, the agent qualifies as prevalently rational; as $k$ approaches zero, the agent qualifies as prevalently biased. The parameter $k$ is in principle agentspecific, and as such indexed by the superscript $i$; it may be taken to reflect the degree of what is called "self-efficacy" (Bandura, 1997) or "perceived behavioural control" (Ajzen, 2005), that is the subjectively held probability than one is capable of executing a certain course of action (in this case, stay married). The higher the degree of self-efficacy or perceived behavioural control, the more accurate is the perception of what one can actually do or not, and therefore the more precise is the estimate of one's chances.

\section{How the possibility of divorce affects the incentives to marry}

Suppose that in our post-industrial society, divorce has just been introduced at time $\theta$. The actual rate of divorce was zero at $\theta-1$, and according to our formulation of the availability heuristic, the perceived rate at period $\theta$ will be zero too - see (26). This seems plausible: no divorce has ever occurred and therefore the biased agents overestimate the frequency of the only type of marriage they can remember - that is, stable marriages. Since however divorces do occur at time $\theta$, the perceived risk of divorce for agents who form their expectations exactly at $\theta$ will be positive and larger than the actual rate of divorce.

Let us now investigate what happens in each of the periods $\theta-1, \theta$ and $\theta+1^{18}$ for agents facing different divorce risks, considering the polar cases of perfect foresight $\left(k^{i}=1\right)$ and perfect bias $\left(k^{i}=0\right)$ - the intermediate cases can be understood as a mix of these two extreme situations. Agents are classified as having high, medium and low risk of divorce; the exact definition and the outcomes are presented compactly in Table 1.

Consider rational agents first. The behaviour changes as the risk of divorce decreases - as we move down from one line to the next (recall that $\nu$ is the true probability of having a good

\footnotetext{
${ }^{18}$ The period $\theta+1$ is representative of all subsequent periods.
} 
agent

rational

biased

period

high risk $(\nu<1 / 2)$

$\begin{array}{llllll}\theta-1 & \theta & \theta+1 & \theta-1 & \theta & \theta+1\end{array}$

medium risk $(1 / 2<\nu<(\zeta+\gamma) /(2 \zeta+\gamma))$

nw nw $n w \quad$ w $\quad$ w $\quad$ nw

low risk $(\nu>(\zeta+\gamma) /(2 \zeta+\gamma))$

w nw nw $\quad$ w $\quad$ w $\quad$ nw

Table 1: Willingness to marry by category of divorce risk

marriage). The first category includes agents who are very prone to divorce: being rational, they clearly aren't willing to marry in any of the three periods under consideration because of (21). The second category includes agents for whom the risk of divorce takes an intermediate value: they are willing to marry at $\theta-1$, but unwilling once divorce is introduced - see (21) and (24). Finally, the third category includes agents with low risk of divorce: under rationality, they are always willing to marry - the couples formed at $\theta$ will divorce at $\theta+1$ with a probability $1-\nu_{t}^{i j}<1 / 2$, but this will not alter the incentives to marry at $\theta+1$.

Under bias, several combinations are possible. We focus here on one which has, in our view, interesting features - all the others can be analysed in a similar way. We have chosen the following case:

$$
\begin{gathered}
p_{t}^{i j}>(\zeta+\gamma) /(2 \zeta+\gamma) \text { at } t=\theta-1, \theta \\
p_{t}^{i j}<(\zeta+\gamma) /(2 \zeta+\gamma) \text { at } t=\theta+1 .
\end{gathered}
$$

This combination may be interpreted as follows. We know that when divorce is not allowed, the availability heuristic induces the agent to overestimate the incidence of stable marriages; this is (28) $a$. Then, at $\theta-1$ and $\theta$ they all should be willing to marry, irrespective of their actual divorce risk, as we report in Table 1. As a consequence, there will be many marriages, and among them a sizeable share will be unstable, as also all agents with medium-to-high divorce risk have married. Therefore, there will be a large actual rate of divorce at $\theta$; this in turn, will generate a low perceived rate of successful marriages at $\theta+1$ - which is $(28) b$. Then, the biased agents will not marry at $\theta+1$, again irrespective of their divorce rate (see the last column of Table 1). Incidentally, notice that at $\theta+1$ biased agents with high and medium divorce risk follow the same course of action that they would take as rational agents, whereas those with low divorce risk follow the opposite path.

We see a clear pattern emerging from Table 1. In a rational world of changes are more nuanced: the agents use all the available information and take a course of action that reflects 
their actual divorce risk (they become more willing to marry as the risk declines). Biased agents act on the basis of a misinterpretation of the evidence they have access to, and do not rely on their actual divorce risk. The introduction of divorce thus generates a sharp change of behaviour for the biased agents - all jump from being willing to being unwilling to marry. Instead, in the case of rational agents only those with intermediate risk change their attitude. Recall however that this is an extreme characterisation producing extreme outcomes; if all agents were fully biased, nobody would marry from $\theta+1$ onward. Of course, there must be partially biased agents who remain willing to marry after the introduction of divorce: to be precise, these will be those for whom

$$
p_{t}^{i j} \geq(\zeta+\gamma) /(2 \zeta+\gamma) \text { at } t=\theta+1
$$

that is, those whose estimated rate of successful marriages is still large enough to be above the threshold identified in Claim 7.

Comparing the outcomes of Table 1, and accounting for the likely behaviour of intermediate types (neither fully rational nor fully biased), it is possible to argue that, depending on whether there is a prevalence of rational or biased agents, we expect differing impacts of divorce on marriage decisions. Under rationality, only the medium-risk agents change their attitude towards marriage when divorce is introduced at $\theta$; so, the model predicts a moderate reduction in the number of marriages. Instead under bias all agents change their attitude, so the the prediction is that the presence of divorce reduces the number of marriages sharply. Indeed, we know that virtually all developed countries have experienced a continuing and significant reduction in the number of marriages in the last decades, and that the fall in the marriage rates begins roughly at the same time as the spread of divorce (see below for a few examples).

A further look at Table 1 indicates also that, as we move towards a prevalence of biased agents, we expect a larger rate of divorce at $\theta$, but not necessarily from $\theta+1$ onwards. Indeed, at $\theta$ biased agents are all willing to marry no matter how risky is their marriage, whereas rational agents only marry if their divorce risk is low; instead, from $\theta+1$ onwards the only difference in behaviour between rational and biased agents concerns the low-risk type, which should affect the overall divorce rate minimally anyway. So, in the rationality case, the divorce rate should be stable over time, whereas in the availability heuristics case should first rise and then slow down.

The stylised facts do not appear to contradict the availabily heuristic assumption. It is often the case in the Western countries that the divorce rate has jumped up after the introduction of 
divorce law or after some drastic procedural simplification, and then has slowed down to lower levels (accompanied by a reduction of the number of marriages). This is for example the pattern followed in all three countries that we mentioned in fn. 3 (Italy, UK, US), where divorce rates went very high in the '70s and have since stabilised at lower levels (see e.g. Smith 1997 for an in-depth analysis of the UK case, and Rasul 2006 for a theoretical discussion that sheds light on many empirical findings for the US and elsewhere). Recall that divorces occur early on in marriage (Becker 1991), so that it takes relatively little time for the divorce rates to adjust in response to changes in the environment.

A competing explanation would be that when divorce law is introduced or divorce is made easier, there is a backlog of unsuccessful marriages that determines the initial jump upwards of the divorce rate; once this first wave has vanished, a trend settles in (this is for example what Smith 1997 argues). This argument may be valid or not, but, mostly, it is difficult to reconcile it with the view of the agent as rational and capable of perfect foresight. First, it would imply that many agents with poor prospects of a good marriage had actually married but in a rational world this should not have happened on a large scale. Second, it would imply that the agents underestimated the cost of divorce, again something that should not happen in a rational world; couples who have had to endure a difficult marriage due to the impossibility of divorce must have found a way of coping with the situation over the years, and it is doubtful that the vast majority of them might want to embark in a divorce at this stage if they are aware of the high costs of the process.

\section{Concluding remarks}

In this paper, we have investigated the question why in the past 40 years or so, divorce has become an increasing popular option in our Western civilization after centuries of stigmatisation. We have argued that this is to be understood in the more general context of the changes brought about by the replacement of informal social protection networks with the formal safety net supplied by the Welfare State. Since the family has lost its previous place as the main provider of social services, marriages have decreased in number, and divorce has become legally possible as well as socially accepted. Furthermore, we noticed that the introduction of divorce has not limited the decrease of the number of marriages, rather has acted as an additional reason for its reduction. This is due to the extremely costly nature of the divorce process (both in monetary and psychological terms): the expected benefit from a marriage appears very small to many 
agents.

As concerns this latter point, we allowed for the possibility that the expected benefit is taken to be smaller than actually is. We compared a case in which agents were able to predict exactly the probability of divorce with another in which, due to the use of an availability heuristic, they overestimated the actual risk of divorce - thereby computing an exceedingly low expected benefit from marriage. We noticed that the predictions of the two versions of the model on how the marriage rate as well as the divorce rate should move over time are somewhat different, and discuss their compatibility with the main stylised facts, concluding that the latter do not imply a straightforward rejection of the availability heuristics hypothesis. The fact that the divorce rate is higher in the first periods of divorce law than in subsequent ones is indeed compatible with this hypothesis. An initial tendency to overestimate the incidence of successful marriage favours the presence of unstable marriages, that necessarily end up, in most cases, with a divorce. In subsequent periods, this tendency vanishes, and is replaced by a tendency to overestimate the risk of divorce; therefore all marriages are discouraged, including in particular the unstable ones, and the rate of divorce goes down.

\section{References}

Akerlof, G., 1980, "A theory of social custom of which unemployment may be one consequence", Quarterly Journal of Economics, 94, 749-775.

Anderberg, D., 2007, "Marriage, divorce, and reciprocity-based cooperation" Scandinavian Journal of Economics 109, 25-47.

Anderberg, D. and A. Balestrino, 2007, "Non-cooperative households and the size and composition of public expenditure", Economics of Governance, 8, 61-81.

Apps, P. and R. Rees, 1999, "On the taxation of trade within and between households", Journal of Public Economics 73, 241-263.

Ajzen, I., 2005, Attitudes, Personality and Behavior, Open University Press, Maidenhead, UK. Balestrino, A., and C. Ciardi, 2008, "Social norms, cognitive dissonance, and the timing of marriage", Journal of Socio-Economics, forthcoming.

Bandura, A., Self-Efficacy: The Exercise of Control, Freeman, New York, NY.

Beck, U. and E. Beck-Gernsheim, 1995, The Normal Chaos of Love, Polity Press, Cambridge,UK. Becker, G., 1991, A Treatise on the Family, Harvard University Press, Cambridge, MA. 
Browning, M. and P.A. Chiappori, 1998, "Efficient intra-household allocations: A general characterization and empirical tests", Econometrica 66, 1241-78.

Cameron, S., 2003, "The economic model of divorce: the neglected role of search and specific capital formation", Journal of Socio-Economics 32, 303-316.

Chiappori, P.A., 1988, "Rational household labor supply", Econometrica 56, 63-90.

Coleman, J. 1990, Foundations of Social Theory, Harvard University Press, Cambridge, MA.

Gilovich, T., D. Griffin and D. Kahneman (eds.), 2002, Heuristics and Biases: The Psychology of Intuitive Judgment, Cambridge University Press, New York, NY.

Kahneman, D., P. Slovic and A. Tversky (eds.), 1982, Judgment under Uncertainty: Heuristics and Biases, Cambridge University Press, New York, NY.

Konrad, K. and K.-E. Lommerud, 1995, "Family policy with non-cooperative families", Scandinavian Journal of Economics 97, 581-601

Konrad, K. and K.-E. Lommerud, 2008, "Love and taxes - and matching institutions", Discussion Paper SP II 2008 - 04, Wissenschaftszentrum Berlin.

LeVine, R., S. Sato, T. Hashimoto and J. Verma, 1995, "Love and marriage in eleven cultures", Journal of Cross-Cultural Psychology, 26, 554-571.

List, J., 2004, "Neoclassical theory versus prospect theory: evidence from the marketplace", Econometrica, 72, 615-625.

Lundberg, S. and R. Pollak, 2001, "Efficiency in marriage", NBER Working Paper no. 8642, Cambridge, MA.

Rasul, I., 2006, "Marriage markets and divorce laws", Journal of Law, Economics, and Organization, 22, 30-69.

Smith, I., 1997, "Explaining the growth of divorce in Great Britain", Scottish Journal of Political Economy, 44, 519-544.

Tversky, A. and D. Kahneman, 1982a, "Availability: A heuristics for judging frequency and probability" in: D. Kahneman, P. Slovic and A. Tversky, Judgment under Uncertainty: Heuristics and Biases, Cambridge University Press, New York, NY, pp. 163-178.

Tversky, A. and D. Kahneman, 1982b, "Judgment under uncertainty: heuristics and biases" in: D. Kahneman, P. Slovic and A. Tversky, Judgment under Uncertainty: Heuristics and Biases, Cambridge University Press, New York, NY, pp. 3-20. 


\section{CESifo Working Paper Series}

for full list see www.cesifo-group.org/wp

(address: Poschingerstr. 5, 81679 Munich, Germany, office@cesifo.de)

2285 Axel Dreher and Stefan Voigt, Does Membership in International Organizations Increase Governments' Credibility? Testing the Effects of Delegating Powers, April 2008

2286 Xavier Freixas and Bruno M. Parigi, Lender of Last Resort and Bank Closure Policy, April 2008

2287 Regina Dionisius, Samuel Muehlemann, Harald Pfeifer, Günter Walden, Felix Wenzelmann and Stefan C. Wolter, Cost and Benefit of Apprenticeship Training - A Comparison of Germany and Switzerland, April 2008

2288 Francesco Daveri and Cecilia Jona-Lasinio, Off-Shoring and Productivity Growth in the Italian Manufacturing Industries, April 2008

2289 Mikael Priks, Do Surveillance Cameras Affect Unruly Behavior? A Close Look at Grandstands, April 2008

2290 Marianna Belloc and Daniela Federici, A Two-Country NATREX Model for the Euro/Dollar, April 2008

2291 Nicolas Treich, The Value of a Statistical Life under Ambiguity Aversion, April 2008

2292 J. Atsu Amegashie, Socially-Tolerable Discrimination, April 2008

2293 M. Hashem Pesaran and Andreas Pick, Forecasting Random Walks Under Drift Instability, April 2008

2294 Steven Brakman, Gus Garita, Harry Garretsen and Charles van Marrewijk, Unlocking the Value of Cross-Border Mergers and Acquisitions, May 2008

2295 Eric O’N. Fisher and Kathryn G. Marshall, The Structure of the American Economy, May 2008

2296 Claudia M. Buch and Martin Schlotter, Regional Origins of Employment Volatility: Evidence from German States, May 2008

2297 Helmuth Cremer, Philippe De Donder, Dario Maldonado and Pierre Pestieau, Taxing Sin Goods and Subsidizing Health Care, May 2008

2298 Reinhilde Veugelers and Frederick van der Ploeg, Reforming European Universities: Scope for an Evidence-Based Process, May 2008

2299 Jon H. Fiva and Lars J. Kirkebøen, Does the Housing Market React to New Information on School Quality?, May 2008 
2300 Tina Klautke and Alfons J. Weichenrieder, Interest Income Tax Evasion, the EU Savings Directive, and Capital Market Effects, May 2008

2301 Harald Badinger and Peter Egger, GM Estimation of Higher Order Spatial Autoregressive Processes in Panel Data Error Component Models, May 2008

2302 Jan K. Brueckner, Slot-Based Approaches to Airport Congestion Management, May 2008

2303 Sören Blomquist, Vidar Christiansen and Luca Micheletto, Public Provision of Private Goods and Nondistortionary Marginal Tax Rates, May 2008

2304 Dan Anderberg and Alessandro Balestrino, The Political Economy of Post-Compulsory Education Policy with Endogenous Credit Constraints, May 2008

2305 Tomer Blumkin, Yoram Margalioth and Efraim Sadka, The Role of Stigma in the Design of Welfare Programs, May 2008

2306 Vesa Kanniainen and Paolo M. Panteghini, Tax Neutrality: Illusion or Reality? The Case of Entrepreneurship, May 2008

2307 Thomas Dohmen, Armin Falk, David Huffman and Uwe Sunde, The Intergenerational Transmission of Risk and Trust Attitudes, May 2008

2308 Guglielmo Maria Caporale and Mario Cerrato, Using Chebyshev Polynomials to Approximate Partial Differential Equations, May 2008

2309 Peter Egger and Doina Maria Radulescu, Labour Taxation and Foreign Direct Investment, May 2008

2310 Laurent Linnemer, Dissipative Advertising Signals Quality even without Repeat Purchases, May 2008

2311 Jordi Jofre-Monseny and Albert Solé-Ollé, Which Communities should be afraid of Mobility? The Effects of Agglomeration Economies on the Sensitivity of Firm Location to Local Taxes, May 2008

2312 Andreas Haufler and Ferdinand Mittermaier, Unionisation Triggers Tax Incentives to Attract Foreign Direct Investment, May 2008

2313 Ronel Elul and Piero Gottardi, Bankruptcy: Is it enough to Forgive or must we also Forget?, May 2008

2314 Andreas Irmen and Johanna Kuehnel, Productive Government Expenditure and Economic Growth, May 2008

2315 Beate Henschel, Carsten Pohl and Marcel Thum, Demographic Change and Regional Labour Markets: The Case of Eastern Germany, May 2008 
2316 Gabriel Felbermayr, Wido Geis and Wilhelm Kohler, Restrictive Immigration Policy in Germany: Pains and Gains Foregone?, May 2008

2317 Michael Hofmann, Gerhard Kempkes and Helmut Seitz, Demographic Change and Public Sector Budgets in a Federal System, May 2008

2318 Paul De Grauwe, Macroeconomic Modeling when Agents are Imperfectly Informed, June 2008

2319 Johann K. Brunner and Susanne Pech, Optimum Taxation of Inheritances, June 2008

2320 Thomas Eichner and Marco Runkel, Corporate Income Taxation of Multinationals in a General Equilibrium Model, June 2008

2321 Rainald Borck and Matthias Wrede, Subsidies for Intracity and Intercity Commuting, June 2008

2322 Patricia Apps and Ray Rees, Testing the Pareto Efficiency of Household Resource Allocations, June 2008

2323 Amihai Glazer, Vesa Kanniainen and Panu Poutvaara, Firms' Ethics, Consumer Boycotts, and Signalling, June 2008

2324 Claudia M. Buch, Jörg Döpke and Kerstin Stahn, Great Moderation at the Firm Level? Unconditional vs. Conditional Output Volatility, June 2008

2325 Helmuth Cremer, Philippe De Donder, Dario Maldonado and Pierre Pestieau, Forced Saving, Redistribution and Nonlinear Social Security Schemes, June 2008

2326 M. Hashem Pesaran and Paolo Zaffaroni, Optimal Asset Allocation with Factor Models for Large Portfolios, June 2008

2327 Harald Badinger and Peter Egger, Horizontal versus Vertical Interdependence in Multinational Activity, June 2008

2328 Jan K. Brueckner and Harris Selod, A Theory of Urban Squatting and Land-Tenure Formalization in Developing Countries, June 2008

2329 Paolo M. Panteghini, Corporate Debt, Hybrid Securities and the Effective Tax Rate, June 2008

2330 Guglielmo Maria Caporale, Juncal Cuñado and Luis A. Gil-Alana, Modelling Long-Run Trends and Cycles in Financial Time Series Data, June 2008

2331 Avi Ben-Bassat and Momi Dahan, Social Identity and Voter Turnout, June 2008

2332 Martin R. West and Ludger Wößmann, "Every Catholic Child in a Catholic School”: Historical Resistance to State Schooling, Contemporary Private Competition, and Student Achievement across Countries, June 2008 
2333 Erkki Koskela and Panu Poutvaara, Outsourcing and Labor Taxation in Dual Labor Markets, June 2008

2334 Philippe Choné and Laurent Linnemer, Optimal Litigation Strategies with Signaling and Screening, June 2008

2335 Albert Solé-Ollé and Pilar Sorribas-Navarro, Does Partisan Alignment Affect the Electoral Reward of Intergovernmental Transfers?, June 2008

2336 Antonio Cabrales and Piero Gottardi, Markets for Information: Of Inefficient Firewalls and Efficient Monopolies, June 2008

2337 Sumon Majumdar and Sharun W. Mukand, The Leader as Catalyst - on Leadership and the Mechanics of Institutional Change, June 2008

2338 Ulrich Hange, Tax Competition, Elastic Labor Supply, and Growth, June 2008

2339 Guy Laroque and Bernard Salanié, Does Fertility Respond to Financial Incentives?, June 2008

2340 Adriano Paggiaro, Enrico Rettore and Ugo Trivellato, The Effect of Extending the Duration of Eligibility in an Italian Labour Market Programme for Dismissed Workers, June 2008

2341 Helmut Seitz, Minimum Standards, Fixed Costs and Taxing Autonomy of Subnational Governments, June 2008

2342 Robert S. Chirinko, Leo de Haan and Elmer Sterken, Asset Price Shocks, Real Expenditures, and Financial Structure: A Multi-Country Analysis, July 2008

2343 Wolfgang Leininger, Evolutionarily Stable Preferences in Contests, July 2008

2344 Hartmut Egger and Udo Kreickemeier, Fairness, Trade, and Inequality, July 2008

2345 Ngo Van Long and Bodhisattva Sengupta, Yardstick Competition, Corruption, and Electoral Incentives, July 2008

2346 Florian Baumann, Employment Protection: The Case of Limited Enforceability, July 2008

2347 Alessandro Balestrino, Cinzia Ciardi and Claudio Mammini, On the Causes and Consequences of Divorce, July 2008 